\title{
Social Anxiety and Interpersonal Relationship of Women with PCOD
}

\author{
U.K.Kamathenu ${ }^{1}$, A. Velayudhan ${ }^{2}$, K.V. Krishna ${ }^{3}$, R.Nithya ${ }^{3}$ \\ ${ }^{I}$ Research Assistant, IMPRESS-ICSSR and Research Scholar, Department of Psychology, Bharathiar University, \\ Coimbatore, ${ }^{2}$ Professor and Head, ${ }^{3}$ Assistant Professor, Department of Psychology, Bharathiar University, \\ Coimbatore
}

\begin{abstract}
Every women needs a peaceful life that includes healthy mental health and physical health. Any The kind of disturbance in these health may affect their happiness in their lives. One such disease is the Polycystic ovary syndrome (PCOS/PCOD), it has become the major disease that affected the millions in the recent years. Generally, it is caused by the hormone irregularities which is due to the production of high level of male hormones. The symptoms affects the self esteem and relationship which results in anxiety and relationship issues in women. Especially, these women step into social anxiety and Interpersonal relationship issues. Social anxiety includes the symptoms of anxiety, fear of facing social situations, meeting new people and doing daily routine is front of others. The Interpersonal relationship is the bondship maintained with the people around us. The women with PCOD breaks the bond and fall as the victim for the relationship issues. The aim of the study is to compare and evaluate Social Anxiety and Interpersonal relationship among PCOD Women and Women without PCOD. By using convenience sampling women aging from 22 to 45 years were identified. The tools which are intended to used for present study are social anxiety questionnaire for adults and Relationship assessment scale. Results were analyzed using SPSS 20 version. The results reported that there is no correlation between the Social Anxiety and Interpersonal Relationship. And Significance difference existed between the PCOD Women and Healthy Control and indicated Moderate level of Social Anxiety in PCOD Women and Healthy controls and High level of Interpersonal Relationship in PCOD Women and Moderate level of Interpersonal Relationship in Healthy Women.
\end{abstract}

Keywords: PCOD women, social anxiety, Interpersonal relationship, Healthy Controls.

\section{Introduction}

Every individual needs a healthy life that makes them to stay happy and satisfied. As the interpretation of this, arises the disorders that makes destructive changes among the lives of people who get affected with disorders. In this way, Women are exposed to various disorders and one among them is Polycystic ovary syndrome(PCOS) which is the common endocrine disorder that affects $5 \%-10 \%$ of women of reproductive age. These women undergo wide spectrum of signs and symptoms that are associated with the disturbances of reproductive, endocrine and metabolic functions. Obesity and Insulin resistance act as the basic physiopathological features in patients with PCOS. Several investigators reports that the mental well-being of Polycystic ovary syndrome women are reduced due to the symptoms of infertility, hirsutism and acne that occurs in them. While other investigators specifies that PCOD women suffer with low level of quality of life(QOL), impaired emotional well-being and reduction in the level of sexual satisfaction. Women with PCOS also reported for increased level of depression and psychological distress which are due to the physical appearance of hyperandrogenism also adding obesity, hirsutism, cystic acne, seborrhea and hair loss that influencing feminine identity ${ }^{1}$. This endocrine disorder is most common in women which shows its prevalence rate as $15 \%-20 \%$ among the infertile women ${ }^{2}$ whereas it shows higher prevalence of $6 \%-10 \%$ in obese women who are of reproductive age group ${ }^{3}$. 
In Worldwide, Polycystic ovary syndrome(PCOS) affects approximately $7 \%$ of women of reproductive age group and stands as a complex genetic disease. The main clinical features of this heterogeneous disorder are menstrual irregularities, subfertility, hyperandrogenism and hirsutism ${ }^{4}$. PCOS women had reported to have anxiety or depressive disorders when they are compared with general population in the Cross-sectional epidemiological studies $^{5}$. Women with PCOS also exhibit various symptoms that includes amenorrhea, oligomenorrhea, hirsutism, obesity, infertility, anovulation and acne which results with symptoms of depression, marital and social maladjustment and impair sexual functioning. In Women with PCOS, the prevalence of depression is high and it varies from $28 \%$ to $64 \%$ where as the prevalence of anxiety ranges from $34 \%$ to $57 \%$. Specifically women with PCOS are identified to be at an increased risk of social phobia and suicide attempts. The reasons for higher prevalence of anxiety and depression among the women with PCOS are found to be complex. It is stated that physical symptoms experienced by PCOS women are likely to be the cause of psychological distress. On the other hand, acne, hirsutism and BMI have been associated to increased symptoms of psychological distress. This proves that multiple factors contribute in women with PCOS for the high prevalence of both anxiety and depression ${ }^{6}$. Social Anxiety disorder which is also referred to as Social Phobia, is a fear which is persistent that appears in an individual for one or more social situations where embarrassment may occur and the fear or anxiety is out of proportion to the threat that is posed by the social situation which is as determined by the cultural norms of the person ${ }^{7}$. Many patients with PCOS exhibited depression and anxiety that may coexist along with the other mood disorders that includes obsessive compulsive disorder, Somatization, social phobia and panic disorder ${ }^{8}$. Women who are suffering from hirsutism, tend to exhibit psychotic symptoms more often and show increased levels of anxiety and tension. Patients who indicated the symptoms of hyperandrogenemia are more prone to social phobia and also experience serious problems of identity ${ }^{9}$. Interpersonal relationship is the social and emotional interaction between which corresponds the two or more individuals in an environment. The challenges to feminine identity that includes hirsutism, menstrual problems create a major effect on mood, relationships and psychological wellbeing ${ }^{10}$.

\section{Method}

\section{Objectives of the Study}

The aim of the present study is to compare Social Anxiety and Interpersonal Relationship among PCOD Women.

\section{The Objectives are:}

- Describe the level of Social Anxiety and Interpersonal Relationship of PCOD Women and Healthy Women.

Compare the level of Social Anxiety and Interpersonal Relationship of PCOD Women and Healthy Women.

\section{Hypotheses:}

1. There will be a significant difference between PCOD Women and Healthy Controls in Social Anxiety.

2. There will be a significant difference between PCOD Women and Healthy Controls in Interpersonal Relationship.

3. There will be a significant relationship between Social Anxiety and Interpersonal Relationship.

\section{Sample}

The samples for this study was PCOD Women and Healthy Women. A total of 26 participants were identified from the Hospital of Tamil Nadu state for the present study. Of the total 26 samples, 13 each were PCOD Women and Healthy controls. The age range of the samples were 25 to 45 years with a mean age of 35 years. The Convenience sampling design was used for the present study.

\section{TOOLS}

1) Social Anxiety Questionnaire for adults (SAQ-A30)(2010)

2) Relationship Assessment Scale (1988) 
SOCIAL ANXIETY QUESTIONNAIRE FOR Nadu.

ADULTS (SAQ-A30)

This was developed by Caballo, V. E et.al. It consist of 30 items that helps in measuring the level of Social Anxiety. Respondents should answer each item using a 5-point scale ranging from " 1 " representing no unease, stress or nervousness and "5" representing very high or extreme unease stress, or nervousness.

\section{RELATIONSHIP ASSESSMENT SCALE}

This scale was developed by Hendrick, S. S. A 7-item scale designed to measure general relationship satisfaction. Respondents should answer each item using a 5-point scale ranging from 1 (low satisfaction) to 5 (high satisfaction).

RESEARCH DESIGN: Exploratory research design was followed for the present study.

\section{The inclusion criteria were:}

ü Women diagnosed with PCOD from the Private Hospital.

ü Women without PCOD in Healthy condition.

$\ddot{u} \quad$ Women in the age group between 25 to 45 years.

ü Women belonging to Cuddalore district, Tamil
The exclusion criteria were:

ü Women with other psychiatric illness

ü Women with other Chronic physical illness

ü Adolescents diagnosed with PCOD

\section{PROCEDURE:}

The subjects were collected with few personal data and then they completed Social Anxiety Questionnaire for adults (SAQ-A30)(2010) and Relationship Assessment Scale (1988). The subjects were instructed not to omit any statements.

\section{Statistical Analysis}

Data was analyzed with the SPSS for Windows Version 20. Mean and Standard Deviation was used to compare groups and Independent ' $t$ ' test was used to test significant difference between groups. Pearson correlation was also used to test the significant relationship between the variables.

\section{Results and Discussion}

The data collected analyzed and the results are discussed accordingly.

TABLE 1: Shows the Correlation between the Variables - Social Anxiety and Interpersonal Relationship.

\begin{tabular}{|c|c|c|c|c|}
\hline \multirow{2}{*}{$\begin{array}{c}\text { VARIABLES } \\
\text { GROUPS }\end{array}$} & \multicolumn{2}{|c|}{ SOCIAL ANXIETY } & \multicolumn{2}{c|}{$\begin{array}{c}\text { INTERPERSONAL } \\
\text { RELATIONSHIP }\end{array}$} \\
\cline { 2 - 5 } & r sig & r & NS \\
\hline $\begin{array}{c}\text { PCOD WOMEN } \\
\text { VS } \\
\text { HEALTHY WOMEN }\end{array}$ & 0.173 & NS & 0.173 & \\
\hline
\end{tabular}

Above table shows that there is no correlation between Social Anxiety and Interpersonal Relationship. This indicates that there is no relationship between Social Anxiety and Interpersonal Relationship. 
TABLE 2: Shows the Mean Value and Standard Deviation Social Anxiety and Interpersonal Relationship for PCOD Women and Healthy Women.

\begin{tabular}{|c|c|c|c|c|c|c|}
\hline \multirow{2}{*}{$\begin{array}{l}\text { VARIABLES } \\
\text { GROUPS }\end{array}$} & \multicolumn{5}{|c|}{ SOCIAL ANXIETY } & \multicolumn{3}{c|}{ INTERPERSONAL RELATIONSHIP } \\
\cline { 2 - 7 } & N & MEAN & SD & N & MEAN & SD \\
\hline PCOD WOMEN & 13 & 92.6 & 13.9 & 13 & 28.8 & 3.3 \\
\hline HEALTHY WOMEN & 13 & 74.4 & 23.5 & 13 & 25.8 & 1.8 \\
\hline
\end{tabular}

It can be inferred from the table 2 that PCOD Women and Healthy Women differ significantly in Social Anxiety and Interpersonal Relationship. The significant difference is beyond 0.05 level. By closely looking at the mean score of Social Anxiety, it is interpreted as Moderate for PCOD Women and Healthy Women. And the Mean score of Interpersonal Relationship is interpreted as High for PCOD Women and Moderate for Healthy Women. With respect to the mean difference between PCOD Women and Healthy Women, the significant difference was seen in the Social Anxiety and Interpersonal Relationship.

TABLE 3: Shows the t- value for the comparison Groups (PCOD Women and Healthy Women) in Social Anxiety and Interpersonal Relationship.

\begin{tabular}{|c|c|c|c|c|}
\hline \multirow{2}{*}{$\begin{array}{c}\text { VARIABLES } \\
\text { GROUPS }\end{array}$} & \multicolumn{2}{|c|}{ SOCIAL ANXIETY } & \multicolumn{2}{|c|}{ INTERPERSONAL RELATIONSHIP } \\
\cline { 2 - 5 } & t-value & sig & t-value & \\
\hline $\begin{array}{c}\text { PCOD WOMEN } \\
\text { VS } \\
\text { HEALTHY WOMEN }\end{array}$ & 2.408 & 0.024 & 2.784 & 0.01 \\
\hline
\end{tabular}

*Significant at 0.05, 0.01 level

The table -3 with the $t$ - value shows that there is significant difference in the groups. As interpreted the Social Anxiety is Moderate for both PCOD Women and Healthy Women. This might be due to life situations they undergo each day. Though several studies reported that women have high level of Social Anxiety, in the present study it is Moderate due to smaller sample group. And the Interpersonal Relationship is interpreted as High for PCOD Women and Moderate for Healthy Women. This indicates that, PCOD have better satisfactory relationship compared to the Healthy Women. Overall, PCOD women get into many other psychological problems as the results of the symptoms of the Polycystic Ovary Syndrome which has to be assessed and treated for their better wellbeing.

Based on specific literature, Anxiety levels, psychological distress which includes the feelings of depression and social fears are particularly at the higher level with PCOS women 11, 12, 13, 14, 15, 16. And many other studies reported for the proportion of the PCOS 
women occurs with clinically suitable psychopathology and impaired emotional well-being 12, 17, 18, 19 . Sonino and his colleagues also showed in their study that anxiety disorders are common among PCOS women and impairment of mental function may occur in these women 20 . These women are at high risk of psychological ill health that brings down their quality of life. Stress Stands as one of the mechanisms that influence psychological disorders through hypothalamic-pituitary-adrenal axis and circadian pattern ${ }^{21}$. Hence, there are multifactors that contribute to the psychological ill health of the PCOD women that has to be identified and taken into consideration at the initial stage for treatment to reduce the severity of those distresses.

\section{Conclusion}

The Study revealed the Level of Social Anxiety and Interpersonal Relationship between PCOD Women and Healthy controls. The results indicates that there is no correlation between the Social Anxiety and Interpersonal Relationship. PCOD Women and Healthy Controls showed significant difference in Social Anxiety and Interpersonal Relationship and reported Moderate level of Social Anxiety in PCOD Women and Healthy controls and High level of Interpersonal Relationship in PCOD Women and Moderate level of Interpersonal Relationship in Healthy Women.

Ethical Clearance- Taken from Doctoral committee constituted by the University

Source of Funding- IMPRESS, ICSSR, New Delhi

\section{Conflict of Interest - Nil}

\section{References}

1. Prathap A, Subhalakshmi TP, Varghese PJ. A cross-sectional study on the proportion of anxiety and depression and determinants of quality of life in polycystic ovarian disease. Indian journal of psychological medicine. 2018 Jun;40(3):257-62.

2. Zangeneh FZ, Jafarabadi M, Naghizadeh MM, Abedinia N, Haghollahi F. Psychological distress in women with polycystic ovary syndrome from Imam Khomeini Hospital, Tehran. Journal of reproduction \& infertility. 2012 Apr;13(2):111.
3. Emeksiz HC, Bideci A, NALBANTOĞLU B, NALBANTOĞLU A, Celik C, Yulaf Y, Çamurdan MO, Cinaz P. Anxiety and depression states of adolescents with polycystic ovary syndrome. Turkish journal of medical sciences. 2018 Jun 14;48(3):531-6.

4. Blay SL, Aguiar JV, Passos IC. Polycystic ovary syndrome and mental disorders: a systematic review and exploratory meta-analysis. Neuropsychiatric disease and treatment. 2016;12:2895.

5. Dokras A. Mood and anxiety disorders in women with PCOS. Steroids. 2012 Mar 10;77(4):338-41.

6. Bazarganipour F, Ziaei S, Montazeri A, Foroozanfard F, Kazemnejad A, Faghihzadeh S. Psychological investigation in patients with polycystic ovary syndrome. Health and quality of life outcomes. 2013 Dec 1;11(1):141.

7. National Collaborating Centre for Mental Health (UK. Social anxiety disorder: recognition, assessment and treatment. British Psychological Society.

8. Brutocao C, Zaiem F, Alsawas M, Morrow AS, Murad MH, Javed A. Psychiatric disorders in women with polycystic ovary syndrome: a systematic review and meta-analysis.

9. Podfigurna-Stopa A, Luisi S, Regini C, Katulski K, Centini G, Meczekalski B, Petraglia F. Mood disorders and quality of life in polycystic ovary syndrome. Gynecological endocrinology. 2015 Jun 3;31(6):431-4.

10. Roessler KK, Glintborg D, Ravn P, Birkebaek C, Andersen M. Supportive relationshipspsychological effects of group counselling in women with polycystic ovary syndrome (PCOS). Communication \& Medicine. 2012 May 1;9(2):125.

11. Jedel E, Waern M, Gustafson D, Landen M, Eriksson E, Holm G, Nilsson L, Lind AK, Janson PO, StenerVictorin E. Anxiety and depression symptoms in women with polycystic ovary syndrome compared with controls matched for body mass index. Human reproduction. $2010 \mathrm{Feb} 1 ; 25(2): 450-6$.

12. Janssen OE, Hahn S, Tan S, Benson S, Elsenbruch S. Mood and sexual function in polycystic ovary syndrome. InSeminars in reproductive medicine 2008 Jan (Vol. 26, No. 01, pp. 045-052). (C) Thieme 
Medical Publishers.

13. Kerchner A, Lester W, Stuart SP, Dokras A. Risk of depression and other mental health disorders in women with polycystic ovary syndrome: a longitudinal study. Fertility and sterility. 2009 Jan 1;91(1):207-12.

14. Himelein MJ, Thatcher SS. Polycystic ovary syndrome and mental health: a review. Obstetrical \& gynecological survey. 2006 Nov 1;61(11):72332.

15. Deeks AA, Gibson-Helm ME, Teede HJ. Anxiety and depression in polycystic ovary syndrome: a comprehensive investigation. Fertility and sterility. 2010 May 1;93(7):2421-3.

16. Rassi A, Veras AB, dos Reis M, Pastore DL, Bruno LM, Bruno RV, de Ávila MA, Nardi AE. Prevalence of psychiatric disorders in patients with polycystic ovary syndrome. Comprehensive psychiatry. 2010 Nov 1;51(6):599-602.

17. Månsson $\mathrm{M}$, Holte $\mathrm{J}$, Landin-Wilhelmsen K, Dahlgren E, Johansson A, Landén M.
Women with polycystic ovary syndrome are often depressed or anxious - a case control study. Psychoneuroendocrinology. 2008 Sep 1;33(8):1132-8.

18. Rosmond R. Role of stress in the pathogenesis of the metabolic syndrome. Psychoneuroendocrinology. 2005 Jan 1;30(1):1-0.

19. Diamanti-Kandarakis E. PCOS in adolescents. Best practice \& research Clinical obstetrics \& gynaecology. 2010 Apr 1;24(2):173-83.

20. Sonino N, Navarrini C, Ruini C, Ottolini F, Paoletta A, Fallo F, Boscaro M, Fava GA. Persistent psychological distress in patients treated for endocrine disease. Psychotherapy and psychosomatics. 2004;73(2):78-83.

21. Sayyah-Melli M, Alizadeh M, Pourafkary N, Ouladsahebmadarek E, Jafari-Shobeiri M, Abbassi J, alsadat Kazemi-Shishvan M, Sedaghat K. Psychosocial factors associated with polycystic ovary syndrome: A case control study. Journal of caring sciences. 2015 Sep;4(3):225. 